\author{
Journal of Current and Advance Medical Research \\ January 2017, Vol. 4, No. 1, pp. 27-30 \\ http://www.banglajol.info/index.php/JCAMR \\ ISSN (Print) 2313-447X
}

Review Article

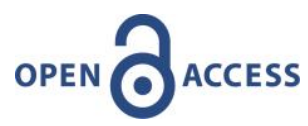

\title{
An Update of Pitted Keratolysis: A Review
}

\author{
Tania Hoque; Bhuiya Mohammad Mahatab Uddin
}

\begin{abstract}
${ }^{1}$ Assistant Professor, Department of Dermatolgy and Venereology, Gonoshasthaya Somaj Vittic Medical college and Hospital, Savar, Dhaka, Bangladesh; ${ }^{2}$ Assistant Professor, Department of Microbiology, Enam Medical College, Savar, Dhaka, Bangladesh
\end{abstract}

[Reviewed: 30 September 2016; Accepted on: 1 October 2016; Published on: 1 January 2017]

\section{Abstract}

Pitted keratolysis is a bacterial infection of the soles of the feet or less commonly, the palms of the hands. Pitted keratolysis is easily identified by its shallow, crater-like pits. Collection of specimen using swab may be helpful to identify causative bacteria and skin scraping is often taken to exclude fungal infection. The diagnosis is sometimes made by skin biopsy revealing characteristic histopathological feature of Pitted Keratolysis. Treatment generally consists of hygienic measures, sometimes supplemented by medication and perhaps on oral medication. This review is aimed to consolidate present information about aetiopathogenesis, diagnosis and management of Pitted Keratolysis. It is worth mentioning that Pitted Keratolysis is non-contagious. [Journal of Current and Advance Medical Research 2017;4(1):27-30]

Keywords: Pitted keratolysis; bacterial infection; non-contagious

Correspondence: Dr. Tania Hoque, Assistant Professor, Dept of Dermatolgy and Venereology, Gonoshasthaya Somaj Vittic Medical college and Hospital, Savar, Dhaka, Bangladesh

Cite this article as: Hoque T, Uddin BMM. An Update of Pitted Keratolysis: A Review. Journal of Current and Advance Medical Research 2017;4(1):27-30

Conflict of Interest: All the authors have declared that there was no conflict of interest.

Contributions to authors: TH has contributed in literature searching \& writing of this manuscript; BMMU has revised the manuscript.

Copyright: (C2017 Hoque \& Uddin. Published by Journal of Current and Advance Medical Research. This article is published under the Creative Commons CC BY-NC License (https://creativecommons.org/licenses/by-nc/4.0/). This license permits use, distribution and reproduction in any medium, provided the original work is properly cited, and is not used for commercial purposes.

\section{Introduction}

Pitted keratolysis was first reported in Ceylonese patients in 1910, by Castellani under the term "Keratoma Plantare Sulcatum", a disease limited to the soles and characterized by small pits which coalesced and formed sulci. In 1930, Acton and McGuire described eight cases of Keratoma Plantare Sulcatum from Bengal ${ }^{1}$. They stated that the pits were associated with an organism belonging to the actinomycetes group and named it Actinomyces Keratolytica spp. In 1931, Acton and McGuire suggested that Actinomyces Keratolytica was the causative agent. With the advent of electron microscopy and special staining method, histologic criteria for diagnosis of Pitted Keratolysis has been determined as a bacterial infection. Pitted keratolysis is caused by cutaneous infection with micrococcus sedentarius (now renamed as Kytococcus sedentarius $)^{2}$. Dermatophilus Congolensis and Corynebacterium species ${ }^{3}$.

The organism Kytococcus sedentarius is a grampositive staphylococcus-related bacterium; it can be grown on tryptase-soy agar. Dermatophilus congolensis is an aerobic gram-positive bacillus, with branching and septate filaments. They form rough, b-hemolytic colonies on horse blood agar. Corynebacterium species are gram-positve, 
catalase-positive, aerobic or facultatively anaerobic, generally non-motile rods ${ }^{4}$.

Numerous studies have been carried out in recent years focusing mainly on structural abnormalities, pathogenesis, diagnostic criteria and clinical therapy of Pitted Keratolysis. However, information in some aspect is still lacking. This present review is emphasized to bridge this gap in knowledge and put forward all the available recommendation in concise manner to explore the way for a future plan of management of Pitted Keratolysis with accuracy.

\section{Pathogenesis}

Under appropriate condition like prolonged occlusion, hyperhidrosis, increase skin surface $\mathrm{pH}^{5}$, these bacteria proliferate and produce proteinase then destroy the stratum corneum, causing pits. D. congolensis liberates keratinase in appropriate substrate. K. sedentarious has been found to produce two keratin-degrading enzymes ${ }^{6}$. They are protease P1 $(30 \mathrm{kd})$ and $\mathrm{P} 2(50 \mathrm{kd})$. The malodor associated with Pitted keratolysis is presumed to be production of sulfur-compound by products, such as thiols, sulfides and thioesteres ${ }^{7}$. In 2006, foot odor without pitted skin changes was discovered to be from overgrowth of Bacillus subtilis and specifically an isovaleric acid produced by staphylococcus epidermidis overgrowth, a normal skin flora.

\section{Clinical Features}

The patients with pitted keratolysis may complain of hyperhidrosis ${ }^{8}$, sliminess, mal odor and occasionally, soreness, itching and pain while walking. However, the pits normally are asymptomatic. Both sides are equally affected, conspicuous, discrete, shallow and circular pits join together at places to produce large erosion. Irritation is minimal. The lesions are composed of numerous small pits or craters present over the soles .They are coalesce in places to produce irregular erosion or sulci, ranging from 0.5 to $7.0 \mathrm{~mm}$ in depth. A variant of madly enlarged lesions, called crateriform pitted keratolysis, which affects the entire width of plantar surface of the foot underlying the metatarsophalangeal joints ${ }^{9}$.

In addition to pits, erythematous to violaceous macules and plaque-like lesions may be present .Sites of involvement are pressure bearing areas such as the ventral aspect of the toe, the ball of foot and the heel, but are also rarely seen on the nonpressure bearing areas of the plantar surface and palms of hands ${ }^{10}$. Interdigital intertrigo and paronychia may coexist but does not influence the onset or course of the disease. Co-existence of Psoriasis has also been reported.

\section{Diagnosis}

Skin biopsy reveals characteristic histopathology ${ }^{11}$. Two types pitted keratolysis can be distinguished histologically; in the superficial or minor type, there is only a small depression due to focal lysis and coccoid bacteria are distributed in groups in some and in chain in others. Whereas in the classical or major type, the organism exhibit dimorphism with septets "Hyphae" as well as coccoid forms, which extent into the stratum corneum forming more definitive pits. Special stains with either a gram stain or Steiner stain will intensely stain the causative organism. Gram stain of Pitted keratolysis shows gram-positive coccal forms and filaments in the stratum corneum. Steiner stain may also highlight the organisms. Some times the organisms may be obvious on routine H-E sections. Culture studies may also be helpful in some cases to confirm the causative organism.

\section{Treatment}

Although no studies are published on hygiene, several protective measures for preventing Pitted keratolysis have been recommended over time.

Topical antibiotics are certainly easy to use and are well accepted by patients .Twice-daily applications of erythromycin or clindamycin are effective. The combination topical gel of clindamycin $1 \%$ - benzyl peroxide $5 \%$ has been found effective in 4 patients $^{13}$ but efficacy required the concurrent use of aluminum chloride hexahydrate solution. Either solution or gel formulations may be used. Topical Mupirocin (Bactroban) also has been effective ${ }^{14}$. For case resistant to topical antibiotics treatments and /or associated with hyper hidrosis, the use of botulinum toxin injections has been effective ${ }^{15}$.

\section{Discussion}

Pitted keratolysis has a worldwide distribution, but is more common among bare footed people living in tropical regions. In a study of 142 homeless men in the Boston area (USA) $20.4 \%$ had Pitted keratolysis ${ }^{16}$. Prevalence rates have ranged from $1.5 \%$ in Japan (evaluation of 4,325 industrial workers) to $2.25 \%$ in New Zealand (random evaluation of 490 subjects $)^{17}$. A much higher prevalence of $53 \%$ was recorded in volunteer 
soldiers in a study conducted in South Vietnam where heat, humidity and boots combine to produce a microenvironment that predisposed to the disease.

\section{Table 1: Recommendation of Pitted} Keratosis

- By wearing boots for as short a period as possible

- Wear socks which effectively absorb sweat i.e. cotton and / or wool

- Wear open-toped sandals whenever possible

- Wash feet with soap or antiseptic cleanser twice daily

- Apply antiperspirant to the feet at least twice weekly.

- Don't wear the same shoes two days in a row-dry them out.

- Do not share foot wear or towel with other

- In 2008, Blaise et al commended that affected patients should wash their socks at a temperature of $60^{\circ} \mathrm{c}$ to kill the Corynebacterium that may be transferred to the socks from skin scaling

- Antifungal and antibacterial dusting powders have also prevent to be effective weapon against the occurrence of this condition

- In some cases, reducing any associated hyperhidrosis with the application of a roll on antiperspirant $20 \%$ aluminum chloride solution, may be help full

- Terrasil (a uniquely effects natural formulate) skin repair protects damaged skin and quickly relieves itch and irritation $^{12}$

Currently, in a study conducted among athletes in Britain $^{18} 25$ of 184 examined had Pitted keratolysis. Prevalence rates of Pitted keratolysis have range from $1.5 \%$ of 4325 Korean industrial worker to $2.25 \%$ (11 of 490 subjecs randomly evaluated) in New Zealand ${ }^{19}$. In addition, $2.6 \%$ of 378 Turkish male adolescent and post adolescent boarding school students had pitted keratolysis and in a $2 \mathrm{yrs}$ study from Belgium, only 4.8 cases of Pitted keratolysis occurred per 1000 dermatology visits. In a study of 1012 patients from Nigeria ${ }^{20}$, only 19 (1.8\%) had Pitted keratolysis.

However 66 (23.3\%) 283 Korean coal miners and $341(42.5 \%)$ paddy field workers in costal South India had Pitted keratolysis due to persistent exposure to moist environment ${ }^{21}$. No race predilection exists for Pitted keratolysis. It is commonly seen during summer and rainy season.
Pitted keratolysis affect any age but adult males with sweaty feet are most susceptible (97\% of the cases). Pitted keratolysis is reported to be more common among bare footed laborers, farmers, marine workers, soldiers and industrial workers wearing occluded shoes for prolonged periods ${ }^{19}$.

Pitted Keratolysis is mainly caused by Coryneform bacteria, though some other bacteria have also been isolated from the lesion, such as Micrococcus sedentarius, Actinomyces keratolytica and Dermatophilus congolensis. Proteolytic enzyme produced by bacteria which digests the keratin, the tough protein that gives resilience to the skin superficial erosions, are seen on the sole and under the toes in Pitted keratolysis. Both sides are equally affected. Pitted Keratolysis is often associated with excessive sweating of palm and soles (palmoplanter hyperhidrosis). Erythrasma and fungal infections of the feet have to be ruled out in cases of Pitted Keratolysis $^{21}$.

Zaias et $\mathrm{al}^{22}$ observing the erosion of the horney layer of planter surfaces, assigned the condition its current name Pitted Keratolysis. International incidence rates of Pitted keratolysis vary significantly based on environment and occupations. Though any age group, but few cases have been reported in the elderly. Theoretically, both male and females should be affected; most written cases report or studies have involved male patients.

A study of physicians treating Dutch army personnel concluded that preventive measures, topical antibiotic therapy, and adequate treatment of hyperhidrosis are the mainstay methods in the management of patients with pitted keratolysis ${ }^{23}$. The treatment of Pitted keratolysis also lacks evidence based studies; however, historically, dermatologists find that topical antibiotics are effective, even if the recommendations presented above are not followed.

\section{Conclusion}

Pitted keratolysis does not typically impede activity, but it can be unpleasant and embarrassing for patients. Informing them about how to keep their feet dry and how to select breathable foot wear is the initial treatment strategy. Instruct Patients with pitted keratolysis should be advised to visit further in case of unsuccessful therapy. Otherwise, care for pitted keratolysis proceeds on an as-needed basis. Dermatologists can diagnose the condition 
with relevant laboratory support and make a treatment plan effective for the individual.

\section{References}

1. Wohlrab J, Rohrbach D, Marsch WC. Keratolysis sulcata (pitted keratolysis): clinical symptoms with different histological correlates. Br J Dermatol 2000;143(6):1348-9.

2. Nordstrom KM, McGinley KJ, Cappiello L, Zechman JM, Leyden JJ. Pitted keratolysis. The role of Micrococcus sedentarius. Arch Dermatol 1987;123(10):1320-5.

3. Rubel LR. Pitted keratolysis and Dermatophilus congolensis. Arch Dermatol 1972;105(4):584-6.

4. Valente NY, Ribeiro Costa A, Pessoa Mendes J. [Pitted keratolysis. Presentation of 2 cases with culture of lesions positive for bacteria of the genus Corynebacterium]. Med Cutan Ibero Lat Am 1983;11(1):61-4.

5. Holland KT, Marshall J, Taylor D. The effect of dilution rate and $\mathrm{pH}$ on biomass and proteinase production by Micrococcus sedentarius grown in continuous culture. J Appl Bacteriol 1992;72(5):429-34.

6. Longshaw CM, Wright JD, Farrell AM, Holland KT. Kytococcus sedentarius, the organism associated with pitted keratolysis, produces two keratin-degrading enzymes. J Appl Microbiol 2002;93(5):810-6.

7. Nordstrom KM, McGinley KJ, Capiello L, Leyden JJ. The etiology of malador associated with pitted keratolysis. Journal of Investigative Dermatology 1986;87:159.

8. Walling HW. Primary hyperhidrosis increases the risk of cutaneous infection: a case-control study of 387 patients. J Am Acad Dermatol 2009;61(2):242-6.

9. Sehgal VN, Ramesh V. Crateriform depression--an unusual clinical expression of pitted keratolysis. Dermatologica. 1983;166(4):209-11.

10. Takama H, Tamada Y, Yokochi K, Ikeya T. Pitted keratolysis: a discussion of two cases in non-weightbearing areas. Acta Derm Venereol 1998;78(3):225-6.

11. de Almeida HL Jr, de Castro LA, Rocha NE, Abrantes VL. Ultrastructure of pitted keratolysis. Int J Dermatol 2000;39(9):698-701.
12. Burkhart CG. Pitted keratolysis: a new form of treatment. Arch Dermatol 1980;116(10):1104.

13. Vlahovic TC, Dunn SP, Kemp K. The use of a clindamycin 1\%-benzoyl peroxide 5\% topical gel in the treatment of pitted keratolysis: a novel therapy. Adv Skin Wound Care 2009;22(12):564-6.

14. Vazquez-Lopez F, Perez-Oliva N. Mupirocine ointment for symptomatic pitted keratolysis. Infection. Jan-Feb 1996;24(1):55.

15. Tamura BM, Cuce LC, Souza RL, Levites J. Plantar hyperhidrosis and pitted keratolysis treated with botulinum toxin injection. Dermatol Surg 2004;30(12 Pt 2):1510-4.

16. Stratigos AJ, Stern R, Gonzalez E, Johnson RA, O'Connell J, Dover JS. Prevalence of skin disease in a cohort of shelter-based homeless men. J Am Acad Dermatol 1999;41(2 Pt 1):197-202.

17. Woodgyer AJ, Baxter M, Rush-Munro FM, Brown J, Kaplan W. Isolation of Dermatophilus congolensis from two New Zealand cases of pitted keratolysis. Australas J Dermatol 1985;26(1):29-35.

18. De Luca JF, Adams BB, Yosipovitch G. Skin manifestations of athletes competing in the summer olympics: what a sports medicine physician should know. Sports Med 2012;42(5):399-413.

19. Eun HC, Park HB, Chun YH. Occupational pitted keratolysis. Contact Dermatitis 1985;12(2):122.

20. Nnoruka EN. Current epidemiology of atopic dermatitis in south-eastern Nigeria. Int J Dermatol 2004;43(10):739-44.

21. Shenoi SD, Davis SV, Rao S, Rao G, Nair S. Dermatoses among paddy field workers--a descriptive, cross-sectional pilot study. Indian J Dermatol Venereol Leprol 2005;71(4):254-8.

22. Zaias N, Taplin D, Rebell G. Pitted keratolysis. Arch Dermatol 1965;92(2):151-4.

23. van der Snoek EM, Ekkelenkamp MB, Suykerbuyk JC. Pitted keratolysis; physicians' treatment and their perceptions in Dutch army personnel. J Eur Acad Dermatol Venereol 2012; 